\title{
Process design for 5 -axis ball end milling using a real-time capable dynamic material removal simulation
}

\author{
B. Denkena ${ }^{1} \cdot$ O. Pape ${ }^{1} \cdot$ A. Krödel ${ }^{1} \cdot$ V. Böß ${ }^{1} \cdot$ L. Ellersiek $^{1}$ (1) $\cdot$ A. Mücke ${ }^{1}$
}

Received: 20 August 2020 / Accepted: 13 November 2020 / Published online: 28 November 2020

(c) The Author(s) 2020

\begin{abstract}
For repairing turbine blades or die and mold forms, additive manufacturing processes are commonly used to build-up new material to damaged sections. Afterwards, a subsequent re-contouring process such as 5-axis ball end milling is required to remove the excess material restoring the often complex original geometries. The process design of the re-contouring operation has to be done virtually, because the individuality of the repair cases prevents actual running-in processes. Hard-to-cut materials e.g. titanium or nickel alloys, parts prone to vibration and long tool holders complicate the repair even further. Thus, a fast and flexible material removal simulation is needed. The simulation has to predict suitable processes focusing shape deviations under consideration of process stability for arbitrary complex engagement conditions. In this paper, a dynamic multi-dexel based material removal simulation is presented, which is able to predict high-resolution surface topography and stable parameters for arbitrary processes such as 5-axis ball end milling. In contrast to other works, the simulation is able to simulate an unstable process using discrete cutting edges in real-time.
\end{abstract}

Keywords Process stability $\cdot$ Milling $\cdot$ Simulation $\cdot$ Dexel

\section{Introduction}

Because of rising demands for economic and sustainable product life cycles, the relevance of efficient repair processes increases [1]. An example for products for which a repair is highly motivated are Blade integrated disks (Blisks) made from Ti-6Al-4V. They are commonly used within compressor stages of jet engines, because of a better power-to-weight ratio. Due to their integral construction and complex geometries, flexible and efficient repair processes are needed if one blade is damaged during operation. Depending on the type of damage, an additional material deposit by welding or brazing might be required to build up the damaged region. Afterwards, the excessive deposit material has to be removed to restore the original geometry. This material removal is carried out using grinding or milling processes. The so-called re-contouring process differs from new part production, because of the uniqueness of each repair case and often-different material properties due to the welding

$\triangle$ L. Ellersiek

ellersiek@ifw.uni-hannover.de

1 Institute of Production Engineering and Machine Tools, Leibniz Universität Hannover, Hanover, Germany or brazing filler [2]. The uniqueness of each repair case also prevents running-in processes, which are commonly used in new part production. Thus, the milling process has to be designed individually for each repair case beforehand. Therefore, a virtual process simulation is considered beneficial [2]. For re-contouring, 5-axis ball end milling is typically used, due to its geometric flexibility and accessibility [2]. Because of vibration prone parts and the often required use of slender tool holders, a stability prognosis of the milling process is required for designing sound re-contouring processes. Additionally, the resulting geometric accuracy and surface topography is of superior importance to minimize scrap and flow loss [3]. In literature, methods exist to predict process stability and surface topography, which can be categorized in analytical and numerical approaches. Analytical methods are often limited to calculate stability lobes without predicting geometric shape errors $[4,5]$. They are often restricted to specific use cases, too. Numerical methods are called material removal simulations (MRS). MRS can predict surface topography and process stability, if a dynamic model is used. Their main advantage over analytical models is their flexibility regarding process kinematics and workpiece geometry. Furthermore, the accuracy of stability prognosis is higher, because non-linear effects can 
be considered using time-domain discretized simulations. However, they are less efficient and need higher computation time [6]. For re-contouring, the application of numericalsimulations is favourable, because of the flexibility needed regarding the complex workpiece geometries as well as the calculation of the engagement parameters considering true milling kinematics. Existing MRS use voxel, dexel or constructive solid geometry (CSG) to discretize the workpiece. The approach by Surmann is one example for the use of CSG including the consideration of tool dynamics [7]. Kersting et al. extends the model by considering workpiece vibrations [8]. However, in both approaches, the cutting edges of the tool are not modelled discretely, preventing the prognosis of surface topography errors due to e.g. cutting edge chipping or helix angle effects. Hense presents a hybrid approach [9], which is based on the works of Siebrecht and Odendahl [10]. Thereby, a CSG workpiece model is used to determine the engagement conditions for calculating process forces with Kienzles force model. This allows deriving the displacements of the tool-workpiece dynamic system using sets of damped driven oscillators. An additional multi-dexel workpiece model is used to consider effects of the discrete modelled cutting edges on the surface topography. However, the long computation time needed is stated as problematically [9]. Montgomery and Altintas presented a MRS considering the flank face-workpiece contact and the resulting ploughing forces [11], which were assumed to be proportional to the yield strength of the material [12]. The workpiece surface could be predicted with a high accuracy. Another MRS considering the contact between flank wear and the workpiece surface was developed by Ko [13]. Stability charts for worn tools were in good agreement with experimental stability charts. However, the surface resulting from the milling process was not analysed. This paper presents a dynamic material removal simulation, which is able to run in real-time, eliminating the disadvantage of long computation times of existing approaches. Despite analyzing process stability, the simulation is able to predict high-resolution surface topography including effects of discrete-modelled cutting edges. This allows an optimization of the re-contouring process also with respect to geometric accuracy.

\section{Experimental setup}

To validate the MRS, the 5-axis machine tool Deckel Maho DMU 125P is used to carry out ball end milling experiments. Therefore, specimen made of AMS $4911 \mathrm{Ti}-6 \mathrm{Al}-4 \mathrm{~V}$ Grade $5\left(90 \times 90 \times 10 \mathrm{~mm}^{3}\right)$ have been machined featuring a tungsten inert gas (TIG) weld. The filler used during TIG welding equals the titanium alloy of the base material, leading to comparable process forces during milling. A two-fluted $10 \mathrm{~mm}$ Seco JH970100 solid carbide ball end mill has been used with a high-temperature steel shrink-fit chuck Garant 30823510 tool holder. The static stiffness of the tool system is $0.7 \mathrm{~N} / \mu \mathrm{m}$. The process forces have been measured with a Kistler 9257B dynamometer. Force coefficients were determined in the simulation based on cutting experiments with varying feed per tooth $f_{\mathrm{z}}$ [14]. An experimental modal analysis has been performed to determine the frequency response functions (FRF) of the tool. Therefore, an impact hammer type PCB Piezotronic 086C03 and a Polytec OFV-3001 + OFV 303 vibrometer system were used. From the FRFs, the modal parameters have been derived using a genetic algorithm. The surface topography is measured using an Alicona InfiniteFocus G5, which is based on focus-variation measurement principle.

\section{Material removal simulation}

The material removal simulation in this paper uses the multi dexel-based approach presented in [15]. Thereby, the tools rake face is discretized with quadrilaterals and the workpiece is discretized using a 3D-dimensional Cartesian dexel grid. The elements of the rake face of each tooth are transformed with discrete time steps $i$ depending on the movement of the tool. For each time step $i$, the tool rotates about the angular step $\mathrm{d} \varphi$. By subtracting the sweep volume of the tool from the workpiece using Boolean operation, the undeformed chip dimensions can be calculated for each element and time step. The differential cutting forces are calculated for each quadrilateral using the process force model by Engin and Altintas

$\left[\begin{array}{l}d F_{\mathrm{t}, \mathrm{n}} \\ d F_{\mathrm{r}, \mathrm{n}} \\ d F_{\mathrm{a}, \mathrm{n}}\end{array}\right]=\left[\begin{array}{l}K_{\mathrm{tc}, \mathrm{n}} \cdot d A_{\mathrm{n}}+K_{\mathrm{te}, \mathrm{n}} \cdot d S_{\mathrm{n}} \\ K_{\mathrm{rc}, \mathrm{n}} \cdot d A_{\mathrm{n}}+K_{\mathrm{re}, \mathrm{n}} \cdot d S_{\mathrm{n}} \\ K_{\mathrm{ac}, \mathrm{n}} \cdot d A_{\mathrm{n}}+K_{\mathrm{ae}, \mathrm{n}} \cdot d S_{\mathrm{n}}\end{array}\right]$

where $d F t$ is the tangential, $d F r$ is the radial and $d F a$ is the axial force, $\mathrm{dA}$ is the chip cross section and $\mathrm{dS}$ the contact length [16]. $K_{\mathrm{ic}}$ and $K_{\mathrm{ie}}$ are calculated based on experimental milling tests. By integrating over all elements, the resulting cutting forces can be obtained. They are used to calculate the displacement of the tool-workpiece system at each time step using sets of driven damped oszillators. To derive the displacement of the tool center point (TCP), the equations of motions have to be solved for each oszillator, wherefore semi-implicit Euler method is used. Exemplarily, the equation of motion for one oszillator is

$m_{\mathrm{x}} \cdot \ddot{x}(t)+d_{\mathrm{x}} \cdot \dot{x}(t)+c_{\mathrm{x}} \cdot x(t)=F_{\mathrm{x}}(t)$

where $m_{\mathrm{x}}$ is the modal mass, $d_{\mathrm{x}}$ the modal damping constant, $c_{\mathrm{x}}$ the modal stiffness, $x$ the displacement and $F_{\mathrm{x}}$ the driving force. By numerical integration using semi-implicit Euler 
$\ddot{x}^{i}=\left(F_{\mathrm{x}}^{i}-d_{\mathrm{x}} \cdot \dot{x}^{i}-c_{\mathrm{x}} \cdot x^{i}\right) \cdot \frac{1}{m_{\mathrm{x}}}$

$\dot{x}^{i+1}=\dot{x}^{i}+\ddot{x}^{i} \cdot \Delta t$

$x^{i+1}=x^{i}+\dot{x}^{i+1} \cdot \Delta t$

the displacement $x^{i+1}$ is calculated using the velocity $\dot{x}^{i+1}$, which leads to faster convergence and thus faster computation in comparison to classical Euler because of better conservation of energy. The maximum passive force as convergence criterion dependent on $\Delta t$ and the integration method for an exemplary process is shown in Fig. 1. For convergence, a time step size of at least $\Delta t=6.5 \times 10^{-5} \mathrm{~s}$ is necessary using semi-implicit Euler method. In comparison, explicit Euler requires a time step size of $\Delta t=1 \times 10^{-7} \mathrm{~s}$. A time step size of $\Delta t=6.5 \times 10^{-5} \mathrm{~s}$ corresponds to an angular step size $\Delta \phi=0.5^{\circ}$, which leads to an acceptable absolute error of the rotational sweep volume approximation using a linear connection of $f_{\text {abs }} \approx 0.1 \mu \mathrm{m}$ as shown in Fig. 1. With $\Delta t=6.5 \times 10^{-5} \mathrm{~s}$, the maximum frequency according to Nyquist-Shannon theorem is $f_{\max }=1 / 2 \Delta t \approx 7690 \mathrm{~Hz}$.
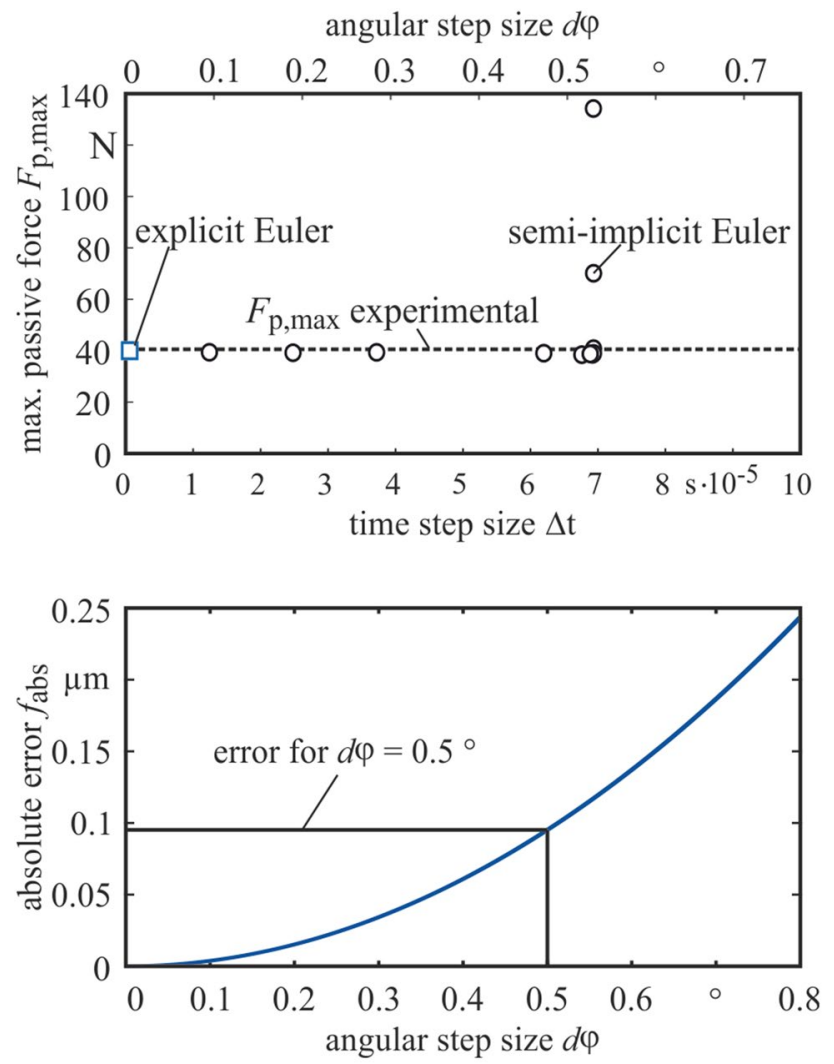

Fig. 1 Convergence and resulting absolute error dependent on angular step size
Thus, a further increase of the time step size using e.g. Runge Kutta methods is not required, depending on the frequency spectrum to be investigated.

\section{Results}

For validating the simulation, the parameters shown in Fig. 2 have been used. Due to the profile of the welded contour, the depth of cut $a_{\mathrm{p}}$ varies with $a_{\mathrm{p}, \max }=0.5 \mathrm{~mm}$. The workpiece is considered stiff as well as the axial direction of the tool. The tools FRFs in $\mathrm{x}$ - and $\mathrm{y}$-direction have been approximated by 28 modes total (Tables 1,2). The five modes with the lowest frequency in $\mathrm{x}$ - and $\mathrm{y}$-direction are the most relevant. The process parameters have been selected according

Table 1 Modal parameters of the tool in $x$-direction

\begin{tabular}{llllll}
\hline No. & $f$ in $\mathrm{Hz}$ & $m$ in $\mathrm{kg}$ & $d$ in Ns/m & $k$ in $\mathrm{N} / \mu \mathrm{m}$ & $\zeta$ in $\%$ \\
\hline 1 & 178 & 180.9 & 9823.8 & 226.5 & 2.4 \\
2 & 211 & 592.4 & 44276.7 & 1038.4 & 2.8 \\
3 & 419 & 5.0 & 1814.0 & 34.4 & 6.9 \\
4 & 681 & 0.2 & 36.6 & 4.3 & 1.8 \\
5 & 760 & 1.2 & 1020.9 & 26.6 & 9.2 \\
6 & 878 & 1.6 & 408.1 & 49.5 & 2.3 \\
7 & 951 & 19.9 & 3247.8 & 711.1 & 1.4 \\
8 & 993 & 252.8 & 102606.6 & 9848.2 & 3.3 \\
9 & 1177 & 22.0 & 6202.4 & 1203.3 & 1.9 \\
10 & 1592 & 3.9 & 4002.6 & 389.4 & 5.1 \\
11 & 1884 & 0.5 & 538.7 & 69.0 & 4.6 \\
12 & 2442 & 0.5 & 398.3 & 121.0 & 2.5 \\
13 & 3171 & 0.4 & 1129.2 & 150.3 & 7.5 \\
14 & 3779 & 0.1 & 278.4 & 46.8 & 7.1 \\
15 & 4233 & 0.1 & 314.5 & 51.5 & 8.1 \\
\hline
\end{tabular}

Table 2 Modal parameters of the tool in $y$-direction

\begin{tabular}{llllll}
\hline No. & $f$ in $\mathrm{Hz}$ & $m$ in $\mathrm{kg}$ & $d$ in Ns/m & $k$ in $\mathrm{N} / \mu \mathrm{m}$ & $\zeta$ in $\%$ \\
\hline 1 & 430 & 6.4 & 2111.3 & 46.7 & 6.1 \\
2 & 689 & 0.2 & 17.9 & 4.4 & 0.9 \\
3 & 827 & 2.4 & 1228.5 & 64.9 & 4.9 \\
4 & 883 & 3.0 & 788.4 & 92.3 & 2.4 \\
5 & 921 & 2.3 & 796.9 & 76.5 & 3.0 \\
6 & 981 & 261.1 & 248151.4 & 9925.4 & 7.7 \\
7 & 1010 & 6.4 & 1153.3 & 255.8 & 1.4 \\
8 & 1871 & 0.4 & 593.6 & 54.2 & 6.4 \\
9 & 2457 & 0.7 & 452.2 & 134.2 & 2.6 \\
10 & 3197 & 0.2 & 662.5 & 61.6 & 10.8 \\
11 & 3723 & 0.1 & 329.4 & 63.8 & 6.0 \\
12 & 3874 & 0.2 & 317.5 & 97.5 & 4.0 \\
13 & 4300 & 0.1 & 134.9 & 82.4 & 2.0 \\
\hline
\end{tabular}




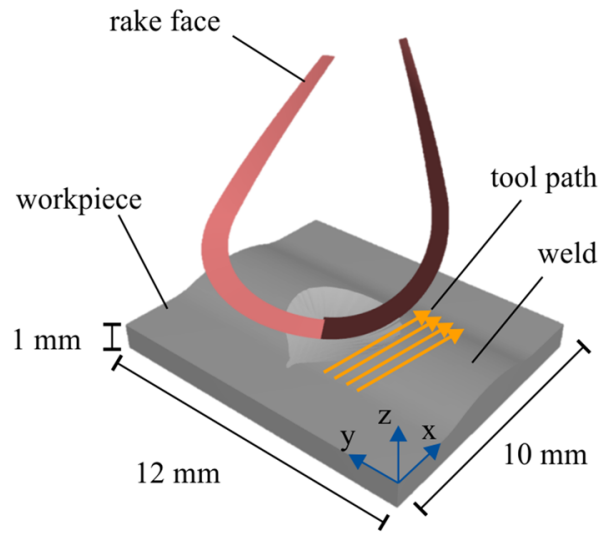

simulation parameters

dexel resolution

$2,048 \cdot 2,048 \cdot 2,048$ Dexel

time step size

tool

tool holder

workpiece

dynamic behaviour

$\Delta \mathrm{t}=5 \cdot 10^{-5} \mathrm{~s}$

Seco JH970100

length $\sim 220 \mathrm{~mm}$

TIG weld flexible tool (28 modes total), rigid workpiece

\section{process parameters}

lead/tilt angle $\lambda / \tau=60 / 0^{\circ}$

max. depth of cut $a_{\mathrm{p}}=0.5 \mathrm{~mm}$

feed per tooth $f_{\mathrm{Z}} \quad=0.5 \mathrm{~mm}$ radial depth $b_{\mathrm{r}} \quad=0.5 \mathrm{~mm}$

cutting speed $v_{\mathrm{c}} \quad=120 \mathrm{~m} / \mathrm{min}$

Mü/94821 C IFW

Fig. 2 Simulation and process parameters

to typical semi-finishing operations when re-contouring parts from Ti-6Al-4V.

\subsection{Process forces and process stability}

For the given process parameters in Fig. 2, the experimental and simulated process forces and their corresponding frequency spectrum are shown in Fig. 3 for one pass of the TIG weld. $F_{\mathrm{f}}$ is the process force in feed direction, $F_{\mathrm{fN}}$ is the process force in feed normal direction and $F_{\mathrm{p}}$ is the passive force.

The maximum forces are reached, when the depth of cut $a_{\mathrm{p}}$ reaches its maximum in the middle of the symmetrical weld shape. The process forces are in good agreement regarding magnitude and frequency. For better comparability, the process forces shown for one tooth pick have been filtered using a low pass filter with a cut-off frequency of $1.4 \mathrm{kHz}$ to minimize the impact of the dynamometer. The graphs underline the accuracy of the chosen approach. The dynamometers eigenfrequency is visible in the frequency spectrum at $f_{\text {dyn }}=2.29 \mathrm{kHz}$. Additional differences arise from the actual geometry of the specimen differing slightly from the ideal CAD-geometry. Moreover, machine inaccuracies and fitting of FRFs as well as specific force coefficients
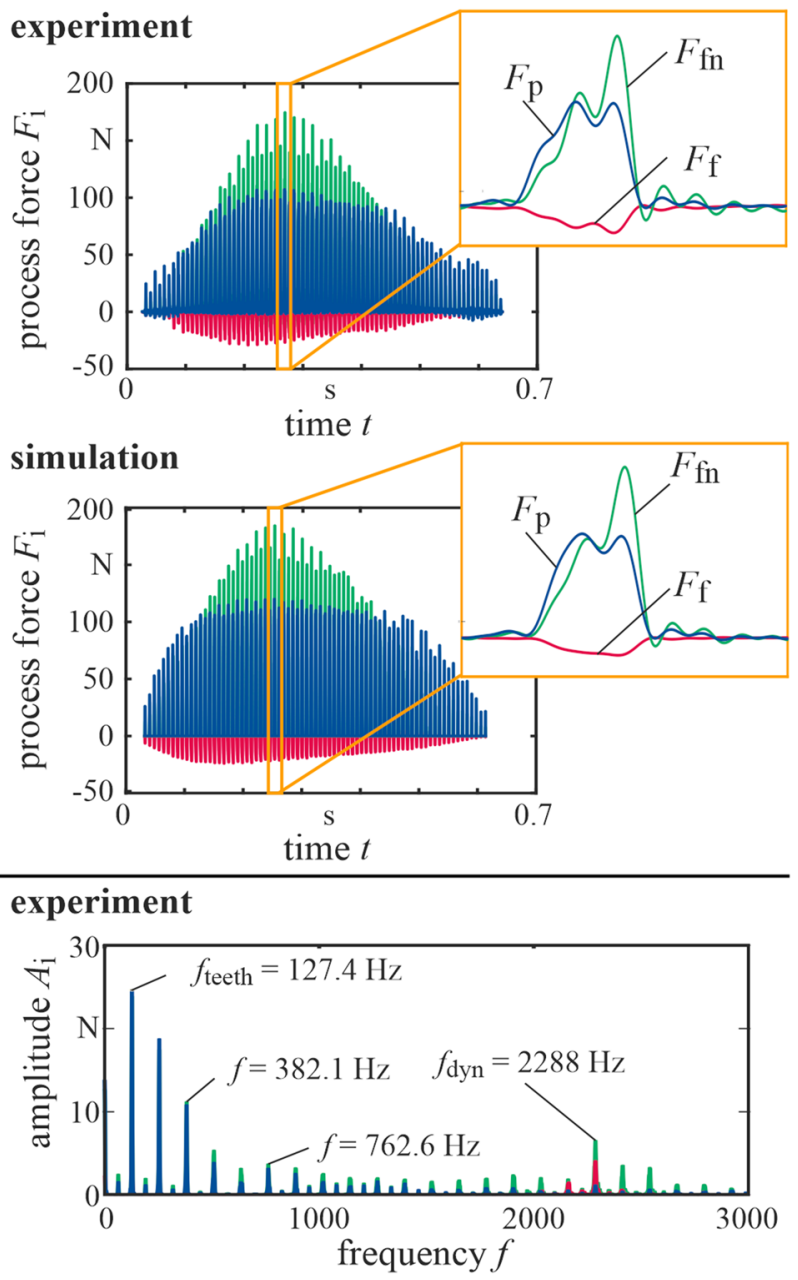

simulation

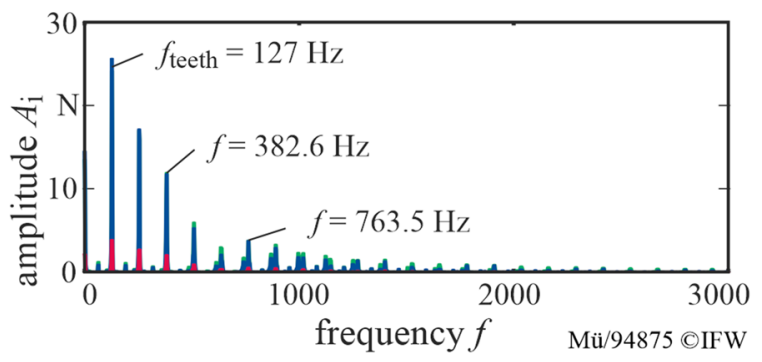

Fig. 3 Process forces and frequency spectrum for one down milling operation

lead to further deviations. For ball end milling, it must be noted that specific force coefficients are required for each set of process parameters individually if a high accuracy is needed. This can be attributed to the varying engagement conditions depending on e.g. tool orientation. To underline the accuracy of the approach, the maximum simulated and measured passive forces as well as process stability are shown in Fig. 4 for additional processes, where $d m$ is down milling, um is up milling, $b_{\mathrm{r}}$ is the radial depth, $\lambda$ is the lead 


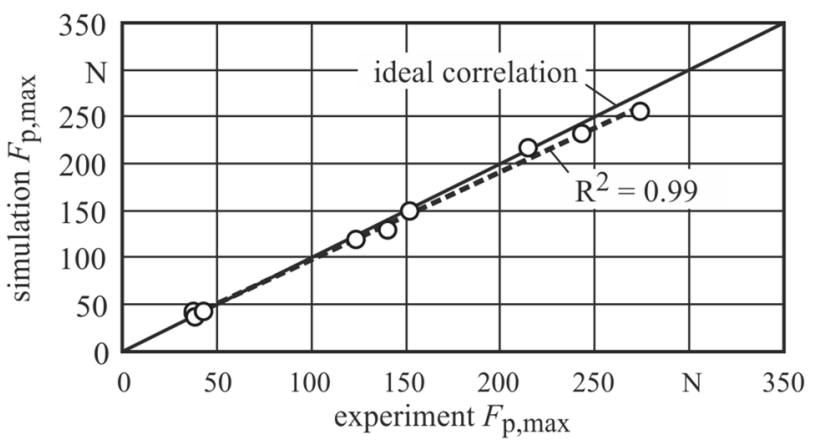

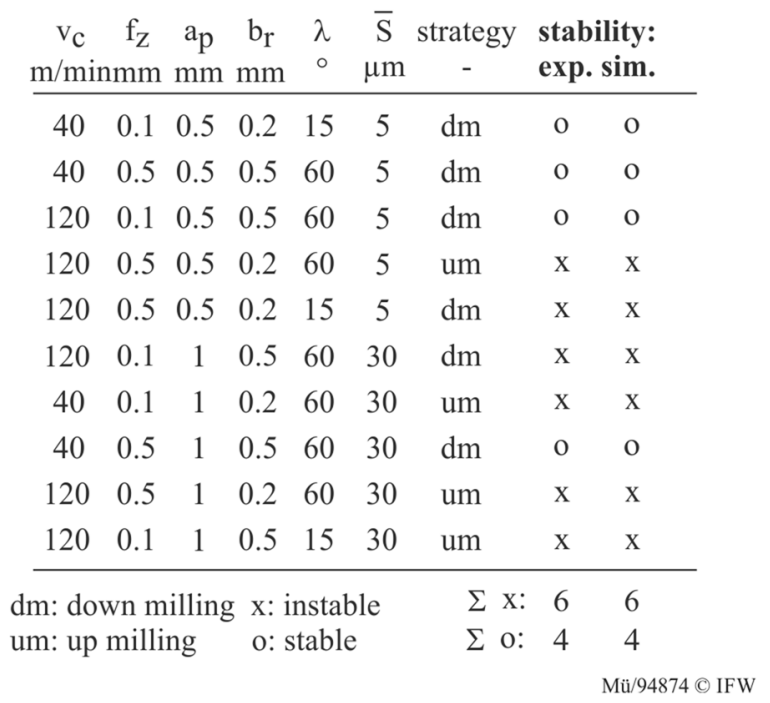

Fig. 4 Prediction of maximum passive force and process stability for different processes with tilt angle $\tau=0^{\circ}$

angle and $\bar{S}$ the cutting edge rounding. The cutting coefficients were calculated for every combination of lead angle and cutting edge rounding $\bar{S}$ individually. Therefore, ploughing effects of the cutting edge rounding and the varying engagement conditions for different lead angles were considered. Due to the high requirements of the process on the geometric accuracy, the main stability criteria is the workpiece surface. If the characteristic surface "bowl structure" of the ball end mill process is clearly distorted, the process is classified as unstable. Additionally, processes were classified as unstable if distinct chatter frequencies were detected. The simulation is able to predict process forces and the corresponding process stability correctly for all different sets of process parameters, regardless of tool orientation, strategy and cutting edge rounding.

\subsection{Surface topography and simulation performance}

Due to the dexel-based approach, an analysis of the resulting surface topography is possible. For the process parameters
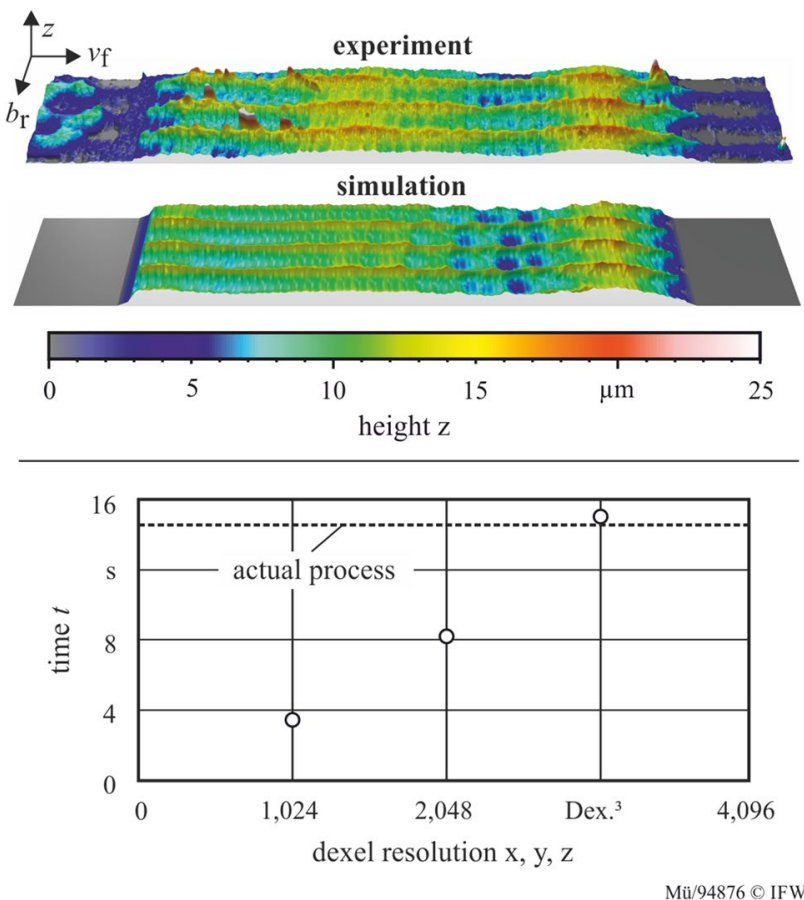

Fig. 5 Surface topography and simulation speed for process parameters from Fig. 2

listed in Fig. 2, the resulting surface topography of the recontoured area is shown in Fig. 5, top. The characteristic shape of the experimental topography is predicted in good agreement using the simulation. The maximum shape deviation occurs when the tool exits the weld in both, simulation and experiment. The maximum error is $\approx 20 \mu \mathrm{m}$ in both cases during the tool exit. A possible explanation is the increased elastic tool deflection during the tool exit. However, it has to be mentioned that the tool orientation strongly influences the shape error at the tool exit. The influence of the tool orientation on the shape error will be subject of future investigations.

Depending on the dexel resolution and tool discretization, a simulation even faster than the actual needed process time is possible as depicted in Fig. 5, bottom. In this example, a dexel resolution of 2,048 in each direction equals $4.9 \mu \mathrm{m} /$ dexel in $\mathrm{x}^{-}, 5.9 \mu \mathrm{m} / \mathrm{dexel}$ in $\mathrm{y}-$ and $0.7 \mu \mathrm{m} / \mathrm{dexel}$ in z-direction. Despite of the high resolution used with 2,048 Dexels in each direction, the simulation needs approximately $8.2 \mathrm{~s}$, whereas the actual process is finished after $14.5 \mathrm{~s}$. The simulation is run on an Intel Core i7 $9900 \mathrm{~K}$ processor using multiple cores and AVX instructions to increase performance. It has to be mentioned that the process parameters already converge at a dexel resolution of 1,024.

An additional example for predicting surface topography is shown in Fig. 6. Thereby, different process paremeters are used if compared to the ones listed in Fig. 2. Besides a lower cutting speed $v_{\mathrm{c}}$ and step over $b_{\mathrm{r}}$, a cutting edge 

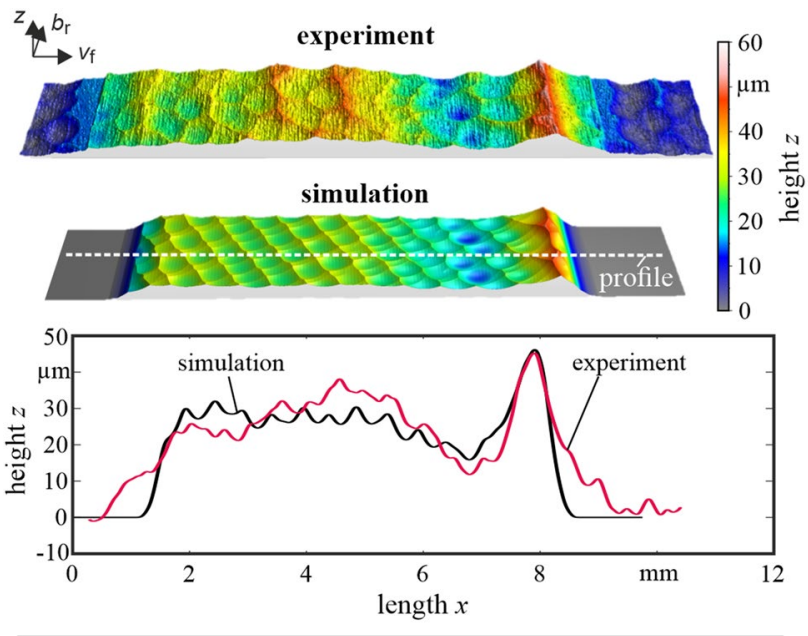

process: ball end milling - re-conturing TIG weld

material Ti-6Al-4V edge rounding

cutting speed $v_{\mathrm{c}}=40 \mathrm{~m} / \mathrm{min}$

edge rounding

$\bar{S}=30 \mu \mathrm{m}$

strategy up milling

depth of cut $a_{p}=1 \mathrm{~mm}$

tool inclination

$\lambda, \tau=55 / 0^{\circ}$

feed per tooth

$f_{\mathrm{z}}=0.5 \mathrm{~mm}$

$b_{\mathrm{r}}=0.2 \mathrm{~mm}$

Mü/94882 @ IFW

Fig. 6 Prediction of surface topography and profile when using cutting edge rounding

rounding $\bar{S}=30 \mu \mathrm{m}$ for inducing compressive residual stresses is applied. However, the cutting edge rounding leads to higher process forces due to additionally ploughing [17], thus tool deviations are increased. Furthermore, when using rounded cutting edges as depicted in Fig. 6 for machining titanium, the elastic material springback $h_{\mathrm{el}}$ has to be considered regarding shape deviations. For $\bar{S}=30 \mu \mathrm{m}$, the elastic material springback is $\approx 9 \mu \mathrm{m}$ according to experimental investigations by [18]. This leads to direct deviations from the nominal depth of cut. Because the dexel-based material removal simulation does not consider any elastic-plastic material behaviour, the profile of the simulation is overall corrected by $\approx 9 \mu \mathrm{m}$. Then, the surface topographies are in good agreement as shown in Fig. 6. For the tool exit on the right side of the topography, the characteristic peak seen in the experiment can be predicted by the simulation. Comparing profiles of both, experiment and simulation, the high accuracy of the simulative approach is underlined.

\section{Conclusion and outlook}

The simulation presented in this paper allows a precise virtual process planning for arbitrary complex processes targeting process stability as well as geometric accuracy. Due to the fast computation, different process parameters can be virtually tested to optimize the actual milling process.
One disadvantage of the presented approach is the need for individual specific force coefficients for each set of process parameters, if a high accuracy is required. Additionally, a precise fitting of the FRFs is necessary, which can be a time consuming task. In future works, process damping effects due to flank face contacts will be included. This will further improve the accuracy of predicting both, process stability as well as surface topography. Besides process design, an additional use of the simulation could be applying the simulation for online process monitoring, where performance is critical e.g. if look-ahead functionalities are demanded.

Acknowledgements The authors kindly thank the German Research Foundation (DFG) for the financial support of the Collaborative Research Center (SFB) 871/3 - 119193472 "Regeneration of Complex Capital Goods" which provides the opportunity of their collaboration in the research projects B2 "Dexterous Regeneration Cell" and C1 "Simulation Based Planning of Re-contouring Metal Cutting Processes".

Funding Open Access funding enabled and organized by Projekt DEAL.

Open Access This article is licensed under a Creative Commons Attribution 4.0 International License, which permits use, sharing, adaptation, distribution and reproduction in any medium or format, as long as you give appropriate credit to the original author(s) and the source, provide a link to the Creative Commons licence, and indicate if changes were made. The images or other third party material in this article are included in the article's Creative Commons licence, unless indicated otherwise in a credit line to the material. If material is not included in the article's Creative Commons licence and your intended use is not permitted by statutory regulation or exceeds the permitted use, you will need to obtain permission directly from the copyright holder. To view a copy of this licence, visit http://creativecommons.org/licenses/by/4.0/.

\section{References}

1. Uhlmann E, Bilz M, Baumgarten J (2013) MRO-challenge and chance for sustainable enterprises. Proc. CIRP 11:239-244

2. Denkena B, Böß V, Nespor D, Flöter F, Rust F (2015) Engine blade regeneration: a literature review on common technologies in terms of machining. Int J Adv Manuf Technol 81:917-924

3. Bons JP (2010) A review of surface roughness effects in gas turbines. J Turbomach 132

4. Altintas Y, Budak E (1995) Analytical prediction of stability lobes in milling. Ann CIRP 44:357-362

5. Insperger T, Stepan G (2011) Semi-discretization for time-delay systems, applied mathematical sciences, 178. Springer, Berlin

6. Altintas Y, Kersting P, Biermann D, Budak E, Denkena B, Lazoglu I (2014) Virtual process systems for part machining operations. CIRP Ann Manuf Technol 63:585-605

7. Surmann T, Biermann D (2008) The effect of tool vibrations on the flank surface created by peripheral milling. CIRP Ann 57:375-378

8. Kersting P, Biermann D (2014) Modeling techniques for simulating workpiece deflections in NC milling. CIRP J Manuf Sci Technol 7:48-54

9. Hense R (2018) Simulation und Optimierung der Fräsbearbeitung von Verdichterschaufeln, Dr.-Ing. Dissertation, Schriftenreihe des ISF, TU Dortmund 
10. Siebrecht T, Kersting P, Biermann D, Odendahl S, Bergmann J (2015) Modeling of surface location errors in a multi-scale milling simulation system using tool model based on triangle meshes. Proc CIRP 37:188-192

11. Montgomery D, Altintas Y (1991) Mechanism of cutting force and surface generation in dynamic milling. Trans ASME 113:160-168

12. Halling J (1975) Principles of tribology. The Macmillian Press Ltd., Hong Kong

13. Ko JH (2015) Time domain prediction of milling stability according to cross edge radiuses and flank edge profiles. Int J Mach Tools Manuf 89:74-85

14. Gradisek J, Kalveram M, Weinert W (2004) Mechanistic identification of specific force coefficients for a general end mill. Int $\mathrm{J}$ Mach Tools Manuf 44:401-414

15. Denkena B, Grove T, Pape O (2019) Optimization of complex cutting tools using a multi-dexel based material removal simulation. Proc CIRP 82:379-382
16. Engin S, Altintas Y (2001) Mechanics and dynamics of general milling cutters. Int J Mach Tools Manuf 41:2195-2212

17. Denkena B, Nespor D, Böß V, Köhler J (2014) Residual stresses formation after re-contouring of welded Ti-6Al-4V parts by means of 5-axis ball nose end milling. CIRP J Manuf Sci Technol 7:347-360

18. Bergmann B (2017) Grundlagen zur Auslegung von Schneidkantenverrundungen, Dr.-Ing. Dissertation, Berichte aus dem IFW, Leibniz University Hannover

Publisher's Note Springer Nature remains neutral with regard to jurisdictional claims in published maps and institutional affiliations. 